\title{
The Impacts of Climate Zone, Wall Insulation, and Window Types on Building Energy Performance
}

\author{
Abid Nadeem ${ }^{1}$, Yerzhan Abzhanov ${ }^{1}$, Serik Tokbolat ${ }^{1,2}$, Mohamad Mustafa ${ }^{2}$ and Bjørn \\ R. Sørensen ${ }^{2}$ \\ ${ }^{1}$ Department of Civil and Environmental Engineering, Nazarbayev University, Nur-Sultan, \\ Kazakhstan \\ ${ }^{2}$ Institute of Buildings, Energy and Material Technology, UiT The Arctic University of \\ Norway, Narvik, Norway \\ abid.nadeemenu.edu.kz
}

\begin{abstract}
Building energy consumption tends to increase over the next few decades due to the increasing level of urbanization and population. These days much attention has been paid to the enhancement of energy performance of residential and non-residential structures. One should consider various factors for proper building thermal design and assessment. In this study, a simulationbased investigation is applied to analyze the influence of building envelope, climate region, and window's physical features on energy performance. Building's energy consumption, thermal comfort of occupants, and amount of $\mathrm{CO}_{2}$ emissions are studied. EnergyPlus tool interfaced with DesignBuilder software was used to perform energy simulations. Annual energy analyses are carried out on the reference house model over the five climate regions from the Koppen-Geiger climate classification map. According to results obtained, climate condition, wall envelope, window type, and window to wall ratio can significantly influence a building's energy performance. Application of insulating materials and the use of specific window type results in considerable energy savings and reduction of $\mathrm{CO}_{2}$ emission amounts.
\end{abstract}

Keywords: Building energy simulation, insulating materials, climate regions, energy performance, energy-saving potential

\section{Introduction}

In recent times, $30-40 \%$ of the total energy produced worldwide is consumed by building sector where heating, ventilation and air conditioning (HVAC) system utilize a significant portion of the energy [1]. It is also responsible for $8 \%$ of energy production related to $\mathrm{CO}_{2}$ emissions. This value may rise since it is anticipated that by 2050, there will be a $50 \%$ increase in global energy consumption [2]. Consequently, there will be more harmful effects on the environment in the future due to increased building energy consumption and growth in fossil fuel demand associated with a higher amount of $\mathrm{CO}_{2}$ emissions. 
During the design stage of buildings, the designers consider many factors that influence the energy performance of buildings. Active techniques of improving the building's energy consumption are about the advancement of HVAC and lighting systems, while passive methods imply the development of building envelope [3]. Saffari et al. [4] stated that, besides climate classification, factors such as elevation from sea level, solar irradiance, and wind profile are essential to improve energy performance in buildings. These factors may need to be investigated for their influence on the building's energy performance.

Heating and cooling energy reductions, and improvement in the thermal comfort of residents may be achieved by introducing modifications into the building envelope [2]. This approach results in significant outcomes since building envelope design influences $20-60 \%$ of building energy consumption [4]. For instance, techniques such as the use of insulation materials and phase change materials in building envelope design can be used [2]. The building envelope is a significant factor influencing its energy performance. Simona et al. [5] investigated that the inclusion of thermal insulation materials into building envelope leads to the reduction of heating and HVAC energy consumption. They analyzed both the application of internal and external insulation techniques in Romanian residential blocks with the result that externally insulated materials had more significant benefits in terms of energy use. Fang et al. [6] performed experimental studies and determined that insulated building envelopes consume less energy in contrast with envelopes without insulation.

Besides, substantial attention has been paid to the effect of climate zones to the energy performance of buildings. Nadeem [7] investigated the relationship between location and energy consumption of a two-story residential building. In this study, analysis of 2 types of wall envelopes (insulated and uninsulated) was carried out among selected six cities (London, Nur-Sultan, Lahore, Seoul, Kuala Lumpur, and Los Angeles) with different climate conditions. Software simulations were performed to examine the effect of locations on indoor thermal comfort. The results showed that the use of insulated envelopes tends to decrease the heating requirement and increase the cooling needs of buildings. Hence, it is suggested that to provide indoor thermal comfort, use of insulation is not appropriate for all environments.

Thus, it is found that the insulated envelope is more appropriate in cold locations as opposed to hot climates. Aldawi et al. [8] have investigated the performance of two current, and four new wall envelopes among six climate zones of Australia which showed that polyurethane insulation materials performed $40 \%$ better than polystyrene insulation in energy savings.

Windows are an essential component of the building envelope. Amaral et al. [9] evaluated the windows' effect on thermal comfort, heating, and cooling energy consumption of the reference room. They concluded that optimal window characteristics could be determined and applied to enhance its energy performance. These characteristics relate to the building's geographical location, orientation, and physical properties. In a study by Gasparella et al. [10], the effect of window features (window to floor area, different glazing systems, orientations and internal gain levels) on cooling and heating energy demand, under the climatic conditions of Paris, Milan, Nice, and Rome, were investigated for 2-storey insulated residential building. They 
82

also provided some solutions for the impaired performance of windows in summer in the form of utilization of shading systems. Tahmasebi et al. [11] proposed that the window to floor area ratio from $34 \%$ and above would not affect energy performance as they demonstrated that there was a gradual increase in energy consumption from $16 \%$ to $34 \%$ window to floor area ratio, while after $34 \%$ there was significant rise in the energy consumption. This observation provided the idea to consider the effect of solar radiation on windows' thermal performance with the purpose that the study may help to reduce heating and electrical lighting loads [12].

Alghoul et al. [13] investigated the effect of window-to-wall (WWR) ratio and window orientation on heating and cooling energy consumption. The analysis was carried out for an office room with an air-filled double-glazed window having a heat transfer coefficient of $2.72 \mathrm{~W} / \mathrm{m}^{2} \mathrm{~K}$ and located in Tripoli, Libya. According to research results, increase in WWR decreased heating energy consumption and increased cooling energy consumption with subsequent increase of annual total energy use.

Other factors such as solar radiation, wind speed, cloud cover, and altitude of a location are noteworthy in building energy use analysis [14]. Westphal and Lamberts [15] carried out a study to predict annual thermal loads of non-residential buildings in Brazil. They generated a method of estimating building's cooling and heating demand based on weather data such as average monthly temperature, relative humidity, pressure, solar irradiance, and cloud formation of a region. Saffari et al. [4], in their study for the application of phase change materials (PCM), determined that more significant energy savings can be achieved in higher altitudes. The effects of solar irradiance and wind conditions were factors for areas in higher elevations. Differences in factors such as solar radiation (Brasilia $266 \mathrm{Wh} / \mathrm{m}^{2}$, Singapore $85 \mathrm{Wh} / \mathrm{m}^{2}$ ), average monthly cloud cover (Brasilia 56\%, Singapore $87 \%$ ) and average monthly humidity (Brasilia 70\%, Singapore 82\%) were also discussed. Moreover, various construction sustainability related aspects were studied in previous research of authors which have influence over the energy performance of buildings [16-17].

Based on the above literature review, it is evident that several factors may influence a building's energy consumption. However, it is not convenient to reflect all of them in one research study. Therefore, this paper evaluates the impact of the location of the structure (predominantly in varying climate zones) and window features that are necessary for the assessment of energy performance of buildings. This study will provide evidence to the importance of these factors in design and assessment of building's thermal performance (heating and cooling energy consumption, indoor thermal comfort of occupants) and amount of $\mathrm{CO}_{2}$ emissions.

\section{Methodology}

\subsection{Locations (climate zones)}

In this study, five cities from different climate zones were selected. These cities are Nur-Sultan, Beijing, Chicago, Singapore, and Valencia. Nur-Sultan is in central Asia and, in general, has a semi-continental climate with hot summers, freezing and dry 
winters. Beijing and Chicago have a humid continental climate, with hot and humid summers, cold and dry winters, while the first is affected by monsoons from the East. Singapore has a humid tropical climate throughout the year with slight variations in temperature and abundant rainfall. The environment of Valencia is considered as arid with little rain, warm winters, and hot, dry summers. The climatic characteristics of these cities are summarized in Table 1.

\subsection{Building Characteristics and Energy Simulation}

3D model and interior partitioning of the building is shown in Figure 1. This reference building is a wood-framed, two-story single-family residential house that is oriented at $0^{\circ}$ to the north. Kitchen, master bedroom, and living room are on the first floor whereas three more bedrooms are on the second floor and the total builtup area is $247 \mathrm{~m}^{2}$. The analysis assumed that the building envelope parameters were same for different locations. The models were built mainly focusing on external walls which were selected from Design Builder software's library, the data on roofs, floors and doors, and other components of the building envelope were assumed to be same regardless of the construction norms and standards of respective countries.

Table 1. Climate Characteristics of Selected Locations

\begin{tabular}{llllll}
\hline & Nur-Sultan & Beijing & Chicago & Singapore & Valencia \\
\hline Koppen Classification & $\mathrm{Dfb}$ & Dwa & Dfa & Af & BSk \\
\hline $\begin{array}{l}\text { Avg. annual } \\
\text { temperature, }{ }^{\circ} \mathrm{C}\end{array}$ & 2.2 & 12.1 & 10 & 26.8 & 17.4 \\
\hline $\begin{array}{l}\text { Warmest average } \\
\text { temperature, }{ }^{\circ} \mathrm{C}\end{array}$ & $20.7(\mathrm{Jul})$ & $26.3(\mathrm{Jul})$ & $23.5(\mathrm{Jul})$ & 27.4 (May) & 24.9 (Aug) \\
\hline $\begin{array}{l}\text { Coldest average } \\
\text { temperature, }{ }^{\circ} \mathrm{C}\end{array}$ & $-21.4(\mathrm{Feb})$ & $-9.3(\mathrm{Jan})$ & $-9.1(\mathrm{Jan})$ & 22.3 (Jan) & 6.3 (Jan) \\
\hline $\begin{array}{l}\text { Annual } \\
\text { precipitation, mm }\end{array}$ & 308 & 610 & 918 & 2378 & 445 \\
\hline $\begin{array}{l}\text { Elevation above sea } \\
\text { level, } \mathrm{m}\end{array}$ & 347 & 43.5 & 179 & 16 & 15 \\
\hline Source: & & & & & \\
\hline
\end{tabular}

Source: en.climate-data.org

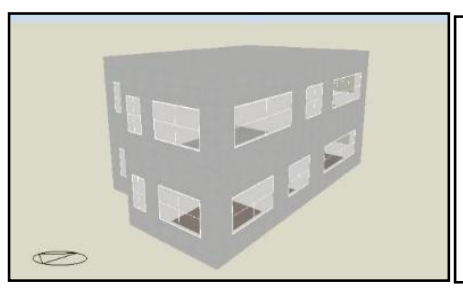

a) 3D model

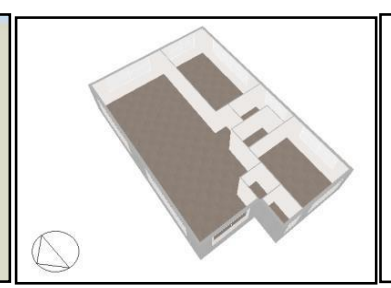

b) $1^{\text {st }}$-floor plan

Fig. 1. Reference building

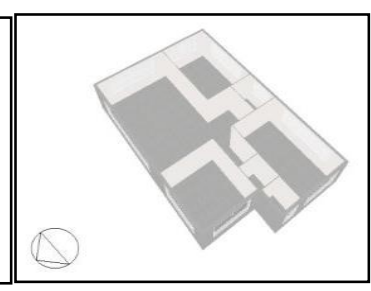

c) $2^{\text {nd-floor plan }}$

For all regions, heating is provided by natural gas while cooling is due to the airconditioning system powered by the electricity. Domestic hot water (DHW) is supplied using a gas boiler. Two types of external wall envelope were analyzed. 
148 One component wall that consists of $20 \mathrm{~mm}$ wood was chosen as the reference wall as it has the most basic configuration. The other wall used insulated polyurethane (IPUF) foam as the primary insulating material. Roof, ground floor, internal wall, and partition wall envelopes were kept unchanged throughout the project. Details of building envelopes are provided in Table 2 .

Effect of window types was investigated using three types of windows with different composition and thermal transmittance values. These windows are double glazed reference window, double glazed window, and triple glazed window. They are analyzed for four different window-to-wall ratios that are $16 \%, 25 \%, 34 \%$, and $41 \%$. Details of windows are provided in Table 3.

It is assumed that the occupancy of the building will be 0.02 people $/ \mathrm{m}^{2}$ which is a typical value for residential houses. Cooling setpoint is at $24{ }^{\circ} \mathrm{C}$ while heating setpoint is at $16{ }^{\circ} \mathrm{C}$. Regular schedules for occupancy, heating, cooling, and lighting are provided in Table 4.

Table 2. Building Envelopes

\begin{tabular}{|c|c|c|}
\hline & Reference wall (Type I) & IPUF \\
\hline External walls & $20 \mathrm{~mm}$ wood & $\begin{array}{l}20 \mathrm{~mm} \text { wood, } 50 \mathrm{~mm} \text { polyurethane } \\
\text { foam, } 100 \mathrm{~mm} \text { glass fiber batt } \\
\text { insulation, } 10 \mathrm{~mm} \text { gypsum board }\end{array}$ \\
\hline Roof & \multicolumn{2}{|c|}{$\begin{array}{l}20 \mathrm{~mm} \text { wood siding }+100 \mathrm{~mm} \text { expanded polystyrene }+50 \mathrm{~mm} \\
\text { polyurethane foam }+15 \mathrm{~mm} \text { gypsum board }\end{array}$} \\
\hline $\begin{array}{l}\text { Slab on grade } \\
\text { floor }\end{array}$ & \multicolumn{2}{|c|}{$\begin{array}{l}150 \mathrm{~mm} \text { concrete slab }+50 \mathrm{~mm} \text { extruded polystyrene }+20 \mathrm{~mm} \\
\text { wooden flooring }\end{array}$} \\
\hline Internal floor & \multicolumn{2}{|c|}{$20 \mathrm{~mm}$ wooden flooring } \\
\hline Partition walls & \multicolumn{2}{|c|}{$15 \mathrm{~mm}$ gypsum board $+20 \mathrm{~mm}$ air gap $+15 \mathrm{~mm}$ gypsum board } \\
\hline
\end{tabular}

Table 3. Window types and physical properties

\begin{tabular}{llll}
\hline Window type & $\begin{array}{l}\text { Composition, } \\
\mathrm{mm}\end{array}$ & $\begin{array}{l}\text { Thermal transmittance, } \\
\mathrm{W} \mathrm{m}^{-2} \mathrm{~K}^{-1}\end{array}$ & $\begin{array}{l}\text { Solar transmittance, } \\
\mathrm{g}\end{array}$ \\
\hline $\begin{array}{l}\text { Reference } \\
\text { window }\end{array}$ & $3 / 13 / 3$ & 1.960 & 0.690 \\
\hline Double glazed & $6 / 13 / 6$ & 2.665 & 0.497 \\
\hline Triple glazed & $3 / 13 / 3 / 13 / 3$ & 0.982 & 0.474 \\
\hline
\end{tabular}

Table 4. Occupancy, heating, cooling, and lighting schedules

\begin{tabular}{ll}
\hline \multicolumn{1}{c}{ Type } & \multicolumn{1}{c}{ Schedule } \\
\hline Occupancy & $0.00-7.00100 \%, 7-9.0050 \%, 9-16.000 \%, 16-19.0080 \%, 19-$ \\
& $00.00100 \%$ \\
\hline Heating & $0-8.00100 \%, 8-16.000 \%, 16-0.00100 \%$ \\
\hline Cooling & $0-8.00100 \%, 8-16.000 \%, 16-0.00100 \%$ \\
\hline Lighting & $0-7.000 \%, 7-9.0050 \%, 9-17.000 \%, 17-20.0050 \%, 20-0.00100 \%$ \\
\hline
\end{tabular}
building materials. It provides a broad range of energy performance modeling, 
evaluation capabilities, and heat transfer computations, advanced HVAC system configurations, algorithms for calculation of thermal comfort of occupants, environmental effect, and cost evaluation [4]. Hence, by using EnergyPlus, under the DesignBuilder interface, it is possible to model the energy systems of the building. The validation of the results was not performed as the software has already been validated by previous studies. However, the further research should attempt to obtain real data from the respective countries on building standards and norm, preferable from real buildings to compare the factual energy consumption.

\section{Results and Discussions}

\subsection{Effect of Location and Wall Envelope on Annual Energy Consumption}

In this section, the results of annual energy consumption simulations for two wall envelopes are presented for each city. Table 5 shows annual heating, cooling, and total energy use for wall envelope in the selected cities. It can be noticed that obtained values of energy demand conform to climate conditions of locations. For instance, for the reference envelope in cold regions with cold winters, energy utilized on heating purpose dominated. From Table 5, it can also be noticed that the insulated wall envelope leads to a reduction in heating energy consumption.

Table 5. Annual energy consumption with selected external wall envelopes

\begin{tabular}{lcccccc}
\hline \multicolumn{1}{c}{ Cities } & \multicolumn{2}{c}{ Heating Energy } & \multicolumn{2}{c}{ Cooling Energy } & \multicolumn{2}{c}{ Total Energy } \\
& $\begin{array}{l}\text { kWh } \\
\text { kWall, }\end{array}$ & $\begin{array}{c}\text { IPUF, } \\
\mathrm{kWh}\end{array}$ & $\begin{array}{c}\text { Ref. wall, } \\
\mathrm{kWh}\end{array}$ & $\begin{array}{c}\text { IPUF, } \\
\mathrm{kWh}\end{array}$ & $\begin{array}{c}\text { Ref. wall, } \\
\mathrm{kWh}\end{array}$ & $\begin{array}{c}\text { IPUF, kWh } \\
\text { (ESP \%) }\end{array}$ \\
\hline $\begin{array}{l}\text { Nur- } \\
\text { Sultan }\end{array}$ & 200,355 & 43,286 & 2,960 & 4,805 & 203,315 & $\begin{array}{c}48,092 \\
(76.4 \%)\end{array}$ \\
\hline Beijing & 67,179 & 7,242 & 6,297 & 7,494 & 73,476 & $\begin{array}{c}14,736 \\
(79.9 \%)\end{array}$ \\
\hline Chicago & 97,010 & 12,052 & 4,278 & 6,311 & 101,288 & $\begin{array}{c}18,363 \\
(81.9 \%)\end{array}$ \\
\hline Valencia & 14,108 & 32 & 7,446 & 9,993 & 21,555 & $\begin{array}{c}10,026 \\
53.5 \%)\end{array}$ \\
\hline Singapore & 0 & 0 & 18,892 & 19,306 & 18,892 & $\begin{array}{c}19,306 \\
(-2.2 \%)\end{array}$ \\
\hline
\end{tabular}

Annual energy saving potentials (ESP) was calculated for IPUF wall envelope and shown in the last column of Table 5. It was estimated by ESP $(\%)=(X-Y) * 100 / X$, where $\mathrm{X}$ is the total energy consumption of the reference envelope, and $\mathrm{Y}$ is the total energy consumption of the wall envelope. Overall, the values of ESP varied slightly among the chosen locations. There is a tangible difference in ESP values between wall without insulation and wall with insulation. It is to be noted that insulated envelope negatively influenced the energy consumption in Singapore. Besides, in all regions, the effect of wall envelope modification was found varying throughout the 
194 year, namely, during the winter period, ESP showed better performance than the 195 summer period.

\section{$196 \quad 3.2 \quad$ Effect of Wall Envelope on Thermal Comfort of Occupants}

197 Relationship between thermal comfort and wall envelope type is represented in 198 Table 6 that shows cooling degree days (CDD, ${ }^{\circ} \mathrm{C}$-day) and heating degree days 199 (HDD, ${ }^{\circ} \mathrm{C}$-day) in each region for all envelopes.

For the reference wall, Nur-Sultan is the city with the lowest CDD, and Singapore is the city with the highest CDD. Due to differences in climate condition, CDD of Singapore is several times greater than of Nur-Sultan, Beijing, Chicago, and Valencia for both wall envelopes. During the summer period, Nur-Sultan is the most comfortable in comparison with other cities. However, for both wall types, NurSultan has the highest HDD value, that means it is the least suitable during the winter period. These results comply with the climatic condition of the regions. For instance, as Nur-Sultan has hot summers and freezing winters, it may need some cooling energy in summer and much heating energy in winter. Due to its tropical climate, Singapore has zero HDD values. Increase in wall thickness and application of insulating materials tend to increase CDD and significantly decrease HDD in all regions, except Singapore where CDD slightly dropped. In Valencia, due to its warm climate, negligible HDD is achieved by using insulation.

Table 6. CDD and HDD for cities and wall envelopes

\begin{tabular}{lrrrr}
\hline & \multicolumn{2}{c}{ Reference wall } & \multicolumn{2}{c}{ IPUF } \\
\hline & CDD & HDD & CDD & HDD \\
\hline Nur-Sultan & 360 & 717 & 487 & 248 \\
\hline Beijing & 582 & 129 & 615 & 25 \\
\hline Chicago & 502 & 216 & 641 & 23 \\
\hline Valencia & 693 & 19 & 808 & 0 \\
\hline Singapore & 1,525 & 0 & 1,412 & 0 \\
\hline
\end{tabular}

\subsection{Effect of Window Characteristics on Annual Energy Consumption}

215 Simulations were carried out for three types of window with varying window to wall ratios (WWR) for reference wall and IPUF wall. When the reference wall envelope was used, increment in WWR led to an increase in cooling energy consumption and decrease in heating and total energy consumption. Figure 2 a depicts changes in annual energy consumption due to the rise in WWR and variation of window type in NurSultan (shown as Astana). When IPUF wall was used, heating, cooling, and total energy consumptions escalated upwards due to increase in WWR. Figure $2 b$ illustrates changes in total energy consumption due to the rise in WWR and alteration of window type in Nur-Sultan. The results show that the increase in WWR tends to raise annual energy consumption in well-insulated buildings, whereas the same drops in uninsulated buildings. For both wall envelopes, Nur-Sultan, Beijing, and Chicago have the lowest annual energy consumption when a triple glazed window was used. In Valencia and Singapore energy performance of double glazed and triple glazed 
Table 8. Amount of $\mathrm{CO}_{2}$ Emissions in Nur-Sultan for Window Types and WWR

\begin{tabular}{lcccccccc}
\hline & Nur-Sultan $\mathrm{CO}_{2}$ emissions, kg (Ref. wall) & \multicolumn{5}{c}{ Nur-Sultan $\mathrm{CO}_{2}$ emissions, kg (IPUF) } \\
\hline & $16 \%$ & $25 \%$ & $34 \%$ & $41 \%$ & $16 \%$ & $25 \%$ & $34 \%$ & $41 \%$ \\
\hline Ref. & 64,713 & 62,551 & 60,390 & 58,716 & 29,926 & 31,033 & 32,220 & 33,169 \\
\hline Double & 65,443 & 63,702 & 61,955 & 60,590 & 30,662 & 32,091 & 33,547 & 34,692 \\
\hline Triple & 64,037 & 61,422 & 58,774 & 56,691 & 29,005 & 29,508 & 30,063 & 30,528 \\
\hline
\end{tabular}

windows were nearly the same. Nevertheless, for both cities, the use of double-glazed window resulted in slightly lower annual energy demand.

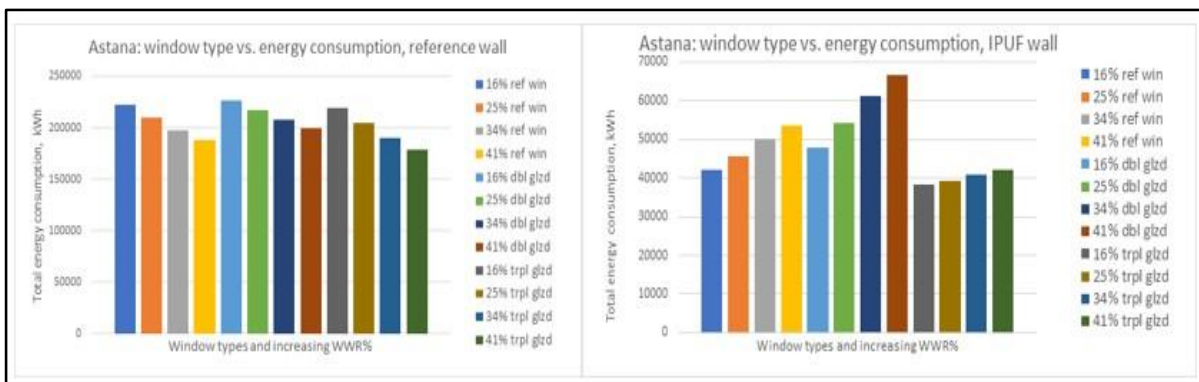

a) For reference wall

b) For IPUF wall.

Fig. 2. Window type vs. annual energy consumption for Nur-Sultan

\subsection{Effect of Window Characteristics on Thermal Comfort of Occupants}

For both wall envelopes, increase in WWR resulted in CDD increment and HDD reduction. When the reference wall is used, in Nur-Sultan, Beijing, and Chicago for all values of WWR, triple glazed window ensured more comfortable conditions whereas, in Valencia and Singapore, the double glazed window showed better performance.

These results can be defined by the sum of CDD and HDD that relates to the total amount of discomfort hours and to the total energy required to retain building temperature within the thermal comfort range. In Table 7, for Nur-Sultan, values of CDD, HDD, and their sum are given as evidence. When IPUF wall is studied, the triple glazed window was the best suitable in Nur-Sultan and Singapore while double glazed showed better performance in Beijing, Chicago, and Valencia.

Table 7. CDD, HDD and their Sum for all WWR in Nur-Sultan with Reference Wall

\begin{tabular}{rrrrrrrrrrrrr}
\hline & \multicolumn{3}{c}{$16 \%$} & \multicolumn{4}{c}{$25 \%$} & \multicolumn{3}{c}{$34 \%$} & \multicolumn{3}{c}{$41 \%$} \\
\hline & CDD & HDD & Sum & CDD & HDD & Sum & CDD & HDD & Sum & CDD & HDD & Sum \\
\hline RW & 275 & 809 & 1,084 & 327 & 750 & 1,077 & 388 & 691 & 1,079 & 442 & 645 & 1,087 \\
\hline Dbl. & 247 & 840 & 1,087 & 276 & 799 & 1,075 & 309 & 757 & 1,066 & 337 & 724 & 1,061 \\
\hline Trpl. & 249 & 822 & 1,071 & 283 & 768 & 1,051 & 322 & 711 & 1,033 & 358 & 665 & 1,023 \\
\hline
\end{tabular}

\subsection{Effect of Window Characteristics on the Amount of $\mathrm{CO}_{2}$ Emissions}


Table 8 shows the amount of $\mathrm{CO}_{2}$ emissions in Nur-Sultan for all three window types and WWR for both reference wall and IPUF wall. For reference wall envelope, increase in WWR leads to a decrease in $\mathrm{CO}_{2}$ emissions. In the case of IPUF wall envelope, the amount of $\mathrm{CO}_{2}$ emissions increased as WWR increased. Moreover, the use of triple glazed window resulted in the lower $\mathrm{CO}_{2}$ emissions in Nur-Sultan, Beijing, and Chicago for both wall envelopes whereas in Valencia and Singapore, results for double glazed and triple glazed windows were nearly the same. Use of insulating material significantly decreased $\mathrm{CO}_{2}$ emissions. However, insulation did not have a considerable effect in cities with warm climate as Valencia and Singapore (Table 9). These results comply with general climate conditions of cities.

Table 9. Amount of $\mathrm{CO}_{2}$ Emissions in all Cities for Both Wall Types with Reference Window with $\mathrm{WWR}=16 \%$

\begin{tabular}{lcc}
\hline & Reference wall, kg & IPUF wall, kg \\
\hline Nur-Sultan & 64,713 & 29,926 \\
\hline Beijing & 39,545 & 25,542 \\
\hline Chicago & 41,382 & 22,506 \\
\hline Valencia & 28,888 & 25,381 \\
\hline Singapore & 32,803 & 31,051 \\
\hline
\end{tabular}

\section{Conclusions and Recommendations}

The study has shown that taking one component wall that the wall insulation can considerably enhance the energy performance of the building. However, results are not the same for different locations and wall envelopes. For instance, more energy can be saved by using IPUF in Nur-Sultan, Beijing, and Chicago. However, this may not be true for other locations. Use of insulated wall envelopes significantly enhanced the energy performance of buildings in cold regions by substantially decreasing heating loads. There are no significant energy saving outcomes for Singapore with an equatorial hot and humid climate. During summer, the effect of insulation tends to decrease, and ESP approaches zero for some locations. Hence, the efficiency of wall envelopes is highly dependent on materials used as well as climate conditions. Insulated walls tended to increase CDD and significantly decrease HDD in all regions except Singapore, where CDD slightly dropped. As insulation reduced the HDD, it can be stated that such envelopes are best suitable for areas with cold climates.

For reference wall, increase in WWR led to the reduction of annual total energy consumption. However, when the wall envelope with an insulation layer was used, annual energy demand increased with increase in WWR. Thus, it can be concluded that the rise in WWR leads to an increase in annual energy consumption in wellinsulated buildings and decreases yearly energy use in uninsulated structures. For reference wall envelope and IPUF envelope increasing WWR led to the increment of CDD and decline of HDD. For reference wall, the increase in WWR associated with the reduction of $\mathrm{CO}_{2}$ emissions while for IPUF wall it was vice versa. Use of insulating materials considerably reduces the amount of $\mathrm{CO}_{2}$ emissions in regions with cold winters. 
The future research should take into consideration more aspects to come up with more robust results. Also, the study would attempt to analyze the impact of several aspects on energy use in a parametric fashion. For example, changing one variable may positively affect the energy saving while changing the other one may compromise the achieved gains due to contradicting nature between variables. Thus, the future research would take into consideration a combination of variables in order to make general conclusions regarding energy savings.

\section{Acknowledgement}

This research was supported by the Project: Academic Cooperation in Post-graduate Engineering Education (ACE) - CPEA-ST-2019/10029 funded by the Norwegian Agency for International Cooperation and Quality Enhancement in Higher Education (Diku) under Eurasia Programme 2019.

\section{References}

1. Lei, J., Yang, J., Yang, E.H.: Energy performance of building envelopes integrated with phase change materials for cooling load reduction in tropical Singapore. Applied Energy 162, 207-217 (2016)

2. Marin, P., Saffari, M., de Gracia, A., Zhu, X., Farid, M.M., Cabeza, L.F., Ushak, S.: Energy savings due to the use of PCM for relocatable lightweight buildings passive heating and cooling in different weather conditions. Energy and Buildings 129, 274-283 (2016)

3. Sadineni, S.B., Madala, S., Boehm, R.F.: Passive building energy savings: a review of building envelope components. Renewable and Sustainable Energy Reviews 15(8), 3617-3631 (2011)

4. Saffari, M., de Gracia, A., Fernández, C., Cabeza, L.F.: Simulation-based optimization of PCM melting temperature to improve the energy performance in buildings. Applied Energy 202, 420-434 (2017)

5. Simona P.L., Spiru P., Ion IV.: Increasing the energy efficiency of buildings by thermal insulation. Energy Procedia 128, 393-399 (2017)

6. Fang, Z., Li, N., Li, B., Luo, G., Huang, Y.: The effect of building envelope insulation on cooling energy consumption in summer. Energy and Buildings 77, 197-205. (2014)

7. Nadeem, A.: Building energy simulations for different climate zones and building envelopes. $1^{\text {st }}$ International Conference on High Performance Energy Efficient Buildings and Homes (HPEEBH 2018), August 1-2, 2018, Lahore, Pakistan, 77-84. (2018)

8. Aldawi, F., Alam, F., Khan, I., Alghamdi, M.: Effect of climates and building materials on house wall thermal performance. Procedia Engineering, 5th BSME International Conference on Thermal Engineering 56, 661-666 (2013)

9. Amaral, A.R., Rodrigues, E., Gaspar, A.R., Gomes, A.: A thermal performance parametric study of window type, orientation, size, and shadowing effect. Sustainable Cities and Society 26, 456-465 (2016) 
10. Gasparella, A., Pernigotto, G., Cappelletti, F., Romagnoni, P., Baggio, P.: Analysis and modelling of window and glazing systems energy performance for a well-insulated residential building. Energy and Buildings 43, 1030-1037. (2011)

11. Tahmasebi, M.M., Banihashemi, S., Hassanabadi, M.S.: Assessment of the various impacts of window on energy consumption and carbon footprint. Procedia Engineering, $21,820-828$ (2011)

12. Grynning, S., Gustavsen, A., Time, B., Jelle, B.P.: Windows in the building of tomorrow: Energy losers or energy gainers? Energy and Buildings 61, 185-192 (2013)

13. Alghoul, S.K., Rijabo, H.G., \& Mashena, M.E.: Energy consumption in buildings: A correlation for the influence of window to wall ratio and window orientation in Tripoli, Libya. Journal of Building Engineering 11, 82-86 (2017)

14. Zhao, H., Magoules, F.: A review on the production of building energy consumption. Renewable and Sustainable Energy Reviews, 16, 3586-3592 (2012)

15. Westphal, F. S., Lamberts, R.: The use of simplified weather data to estimate thermal loads of non-residential buildings. Energy and Buildings 36(8) 847-854 (2004)

16. Tokbolat, S., Karaca, F., Durdyev, S., Calay, R. Construction professionals' perspectives on drivers and barriers of sustainable construction. Environ Dev Sustain (2019).

17. Tokbolat, S., Karaca, F., Durdyev, S., Nazipov F., Aidyngaliyev I. Assessment of Green Practices in Residential Buildings: A Survey Based Empirical Study of Residents in Kazakhstan. Sustainability. Vol. 10(12), 4383 (2018) 